\title{
Preventing Life-Sustaining Treatment by Default
}

\author{
Ursula K. Braun, MD, MPH ${ }^{1,2}$ \\ Laurence B. McCullough, $\mathrm{PbD}^{3}$ \\ 'Health Services Research and Develop- \\ ment Center of Excellence, Michael E. \\ DeBakey VA Medical Center, Houston, \\ Texas \\ ${ }^{2}$ Section of Geriatrics, Baylor College \\ of Medicine, Houston, Texas
}

${ }^{3}$ Center for Medical Ethics and Health Policy, Baylor College of Medicine, Houston, Texas
Conflicts of interest: authors report none.

\section{CORRESPONDING AUTHOR}

Ursula K. Braun, MD, MPH Sections of Geriatrics and Health Services Research and Development Baylor College of Medicine Houston, TX 77030

ubraun@bcm.edu

\begin{abstract}
Many physicians will at some point care for patients who will receive life-sustaining treatment by default, because there are no instructions available from the patient as to what kind of care is preferred, and because surrogates are likely to ask for everything to be done when they do not know a patient's preferences. We use the methods of ethics informed by qualitative focus group research to identify 5 pathways to life-sustaining treatment by default originating with the patient's preferred decision-making style: deciding for oneself or letting others decide. We emphasize preventing the ethically unwelcome outcome of lifesustaining treatment by default by increasing the frequency with which patients make clear decisions or clearly express their values and goals that they then communicate to physicians or surrogates.
\end{abstract}

Ann Fam Med 2011;9:250-256. doi:10.1370/afm.1227.

\section{INTRODUCTION}

L ife-sustaining treatment by default refers to receiving resuscitation, intubation, and mechanical ventilation, vasopressor and intensive care unit support; and administration of other life-sustaining treatments, such as artificial feeding or transfusions, in the absence of guidance from a seriously ill patient who either did not make decisions or did not, orally or in writing, clearly communicate his or her end-of-life decisions effectively to others. We describe different decision-making pathways taken by the patient that result in the administration of life-sustaining treatment by default.

Life-sustaining treatment by default is fraught with potential ethical conflict that can take a considerable and unwelcome biopsychosocial toll on patients, their surrogates, and clinicians. ${ }^{1-5}$ As a consequence, life-sustaining treatment by default can distort an organization's culture by promoting attitudes of indifference toward patients receiving lifesustaining interventions for whom such interventions make little clinical sense, or by contributing to increased burnout in nursing staff caring for such patients. End-of-life decision making for patients who have not made or communicated their decisions can place an inordinate psychosocial and moral burden on surrogates, who may be struggling with a role they did not want or were unprepared to assume. ${ }^{3,6}$ When surrogates are unable to report a patient's preferences, they can feel overwhelmed, which likely increases requests for everything to be done even when such interventions are thought to be futile. ${ }^{7}$ The ethical challenges of such requests are compounded when physicians label surrogates as difficult or irrational, leading to a breach of trust and problems in communication between clinicians and surrogates. ${ }^{4}$

The purpose of this article is to propose an ethically justified strat$\mathrm{egy}^{8,9}$ to prevent life-sustaining treatment by default. We begin by identifying the concept of life-sustaining treatment as a trial of intervention and describe 3 factors that can combine to create life-sustaining treatment by 
default. We next explain the ethical concept of respect for the patient's autonomy, which we then use to describe distinct pathways to life-sustaining treatment by default that originate in patient autonomy. We close by identifying preventive responses to the ethical challenge of life-sustaining treatment by default.

\section{LIFE-SUSTAINING TREATMENT AS A TRIAL OF INTERVENTION}

Life-sustaining treatment, which is often preceded by resuscitation, should be understood as a trial of intervention that can be stopped at any time if its goals no longer seem achievable. ${ }^{10-12}$ It is undertaken with the short-term goal of preventing imminent death. It is continued as long as it is reasonably expected, in evidencebased clinical judgment, to achieve its long-term goal: an acceptable clinical outcome. An acceptable clinical outcome can be defined from a clinical perspective (based on the ethical principle of beneficence) or the patient's perspective (based on the ethical principle of respect for autonomy). A beneficence-based acceptable outcome means the preservation of at least some interactive capacity that is not overwhelmed by diseaserelated or iatrogenic morbidity, disability, pain, distress, or suffering. ${ }^{13}$ An autonomy-based acceptable outcome means an expected functional status that will result in a quality of life the patient is willing to accept. ${ }^{14}$

Physicians should make evidence-based clinical judgments about discontinuing life-sustaining treatment, especially (but not only) when the limits of such treatment have been reached-when it is no longer reasonably expected that the long-term goal can be achieved from the patient's or the physician's perspective. In both circumstances, physicians should offer the alternative of discontinuing treatment.

\section{THREE FACTORS CONTRIBUTING TO LIFE- SUSTAINING TREATMENT BY DEFAULT}

Three factors can combine to create life-sustaining treatment by default. First is the presumption of preserving life when a patient's preferences are unknown or the prognosis is uncertain. Second is the request to do everything. Some patients do not clearly express and communicate their end-of-life decisions adequately. To compound matters, the patients' surrogate decision makers may find their responsibility burdensome and stressful and cope by requesting everything be done to sustain life. Such requests can also stem from other factors, eg, a particular belief system (It's in God's hands-our duty is to try everything.). Third is the path of least resistance, which in response to requests to do everything, physicians fail to engage surrogates in thinking through the burdens and benefits of life-sustaining treatment, a process that can be time consuming. ${ }^{15}$ The result is administration of what we term life-sustaining treatment by default.

We emphasize that in the real world of uncertain prognosis, even if patients expressed clear preferences, clinical uncertainty or clinician discomfort with committing to a prognosis may lead to life-sustaining treatment. This outcome is not what we mean by life-sustaining treatment by default. For instance, a patient who suffered a massive stroke and has multiple preexisting comorbidities may be unlikely to wake up. The more time passes, the more the odds for a good outcome will likely diminish. Within this scenario, individual physicians will have different comfort zones where they can commit to a prognosis. In addition, patients sometimes do communicate their end-oflife decisions to others, but these decisions are not implemented. Failure to implement patients' clearly expressed and effectively communicated decisions by clinicians or surrogates is not life-sustaining treatment by default, because it overrides patients' preferences and violates their autonomy.

Of the 3 factors that can combine to create lifesustaining treatment by default—preserve life when the patient's preferences are unknown or a prognosis is uncertain, request that physicians do everything to preserve life, and take the path of least resistance-the first is appropriate, but the second and third are candidates for change. Our focus is on the second, the patient-generated pathway, which we characterize as autonomy based.

\section{RESPECT FOR THE PATIENT'S AUTONOMY}

The foundation of preventive ethics in end-of-life decision making is respect for the patient's autonomy. This ethical principle obliges health care professionals to acknowledge and respect the patient's values and beliefs, to provide the patient with information requisite to make an informed choice, to prevent substantial control over or coercion in the patient's decision-making process, and to implement the patient's decision unless there is compelling ethical justification for not doing so. ${ }^{16}$

In the widely used textbook of bioethics, Principles of Biomedical Ethics, Beauchamp and Childress characterize the ethical principle of respect for autonomy as "enabling patients to overcome their sense of dependence and to achieve as much control as they desire." ${ }^{16(\mathrm{p} 104)}$ Culturally sensitive respect for autonomy means "[h]ealth professionals... should never assume that because a patient belongs to a particular community or culture, he or she affirms that community's worldview and values." 16(p106) A key concept for translating respect 
for autonomy into clinical practice is the patient's authority to make decisions, ie, the right to exercise a preferred level of control over the decision-making process and its outcome. ${ }^{16(\mathrm{p} 104)}$ The patient has the right to assert authority over decisions in the manner and to the extent that the patient selects 1 of 2 decision-making styles: retain all decision-making authority, or delegate that authority to others explicitly, implicitly, or by default. These choices can all be autonomous.

\section{PATHWAYS TO LIFE-SUSTAINING TREATMENT BY DEFAULT}

We presented findings from qualitative research that was based on focus groups of racially and ethnically diverse, seriously ill veterans and surrogate decision makers. ${ }^{3,17}$ We used inductive qualitative analysis to develop a conceptual model that identified pathways originating in 2 preferred decision-making styles, which we label in Figure 1 as "I decide" and "let others decide." From these 2 styles we found 5 pathways for end-of-life decision making that vary according to the underlying basis for the preferred decision-making style.

Our research suggests that patients who prefer to decide for themselves are motivated to either take responsibility for their own end-of-life decisions (Figure 1, A) or avoid burdening others with having to make those decisions (Figure 1, B). Patients whose decisionmaking style is to allow others to decide delegate that authority to others explicitly, implicitly, or by default.

Patients who explicitly authorize someone to act on their behalf (Figure 1, C) are aware of who their legal surrogate would be if the legal surrogate is not their preferred surrogate, they either officially name a person or tell their family whom they would like to appoint. These patients are highly likely to have discussed at least their general values with the preferred surrogate. Patients who implicitly authorize someone to act on their behalf (Figure 1, D) know who their legal surrogate is but do not feel the need to appoint that person officially or to give that person specific instructions. They may have complete trust in that person's judgment. Patients who by default allow someone to act on their behalf exercise their autonomy passively. Their unwillingness to broach the subject may reflect a willingness to accept any of their legal surrogate's decisions or may be a form of denial, not wanting to explore what may happen when no longer able to make decisions (Figure 1, E).

Included in Figure 1 are some participants' statements that we interpreted as representing these strategies. In Table 1 we have drawn from our clinical practice examples of patients' responding to palliative care consultations for each of these strategies.
The 5 pathways (A through $\mathrm{E}$ ) have 8 implementation strategies depending on whether the patients have clearly made and effectively communicated a decision about end-of-life care. Finally, these 8 implementation strategies can lead to 1 of 10 outcomes, 5 of which are life-sustaining treatment by default.

Of the life-sustaining treatment by default decisionmaking outcomes, number 5 (Figure 1, bottom right), is intuitively the most obvious. Patients whose decisionmaking style is to let others decide and then to accept a legally assigned surrogate decision maker often have not made end-of-life decisions and thus have nothing to communicate. These patients can be understood as electing to let others decide by default, the minimally autonomous decision-making style. They do not exercise their autonomy as an explicit decision. Surrogates of such patients will have the least information about how to decide and thus may resort to life-sustaining treatment by default.

Number 4 in Figure 1 illustrates an important aspect of life-sustaining treatment by default. Confidence in the legal surrogates' judgment may allow patients to implicitly adopt the let-others-decide style. Surrogates, even without guidance by a patient, might know intuitively what a patient would have wanted; alternatively, the surrogates might be conflicted by having to make a genuine decision in the face of uncertainty and all its attending biopsychosocial burdens. Surrogates sometimes manage the burden by asking that everything be done to sustain life, resulting in life-sustaining treatment by default., 5 Additionally, studies have shown that even when surrogates think they know what a patient would have wanted, patients would actually have chosen differently. ${ }^{18-24}$ In particular, surrogates who are chosen by patients specifically because they are personally close may have a hard time of letting go of their relationship; choosing against life-sustaining treatment may result in a patient's death, thereby severing the relationship. ${ }^{23,24}$ Given that patients elect to trust the judgment of legal surrogates, however, such decisions would not violate the patients' autonomy.

Life-sustaining treatment by default outcome 3 illustrates a scenario in which, despite the best intentions of giving guidance to someone entrusted with decision-making authority, patients may not have wholly communicated end-of-life preferences. Even if a patient formally authorized a surrogate by means of medical power of attorney, life-sustaining treatment by default could occur because the surrogate must make a genuine decision ${ }^{7}$ without sufficient guidance from the patient. Effective verbal communication of at least general values is the key to prevent life-sustaining treatment by default in this pathway. 


\section{Figure 1. Pathways to life-sustaining treatment by default.}

Preferred

decision-making role:

Underlying basis
for the preferred
decision-making role:

\section{Verbatim quotes \\ from focus group \\ research:}

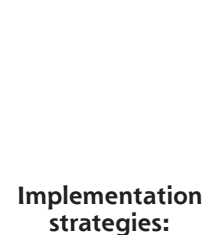

strategies:

Preferred

decision-making role:

Underlying basis

for the preferred

decision-making role:

Verbatim quotes

from focus group

research:

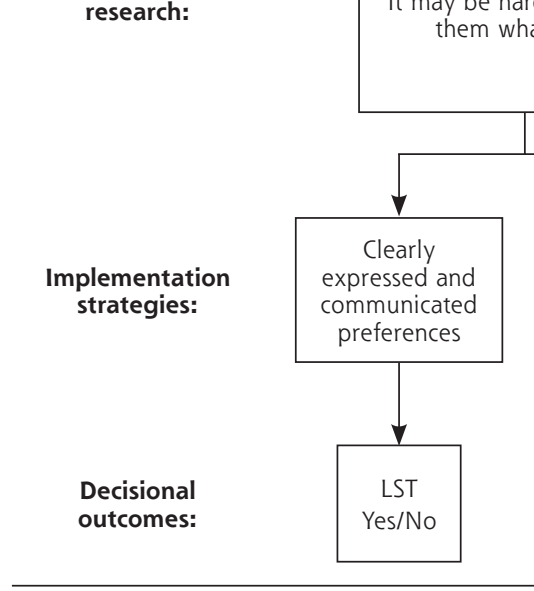

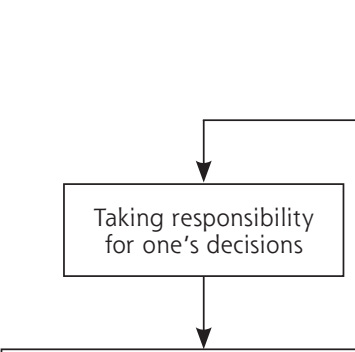

It's my right to decide for myself

I want to make my own decisions It's my own business

A

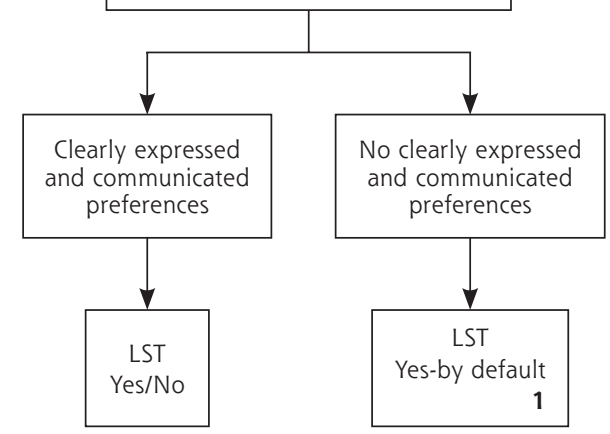

"I decide"

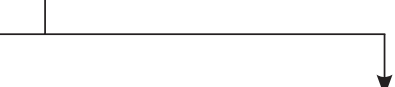

Not wanting to burden others with decision making
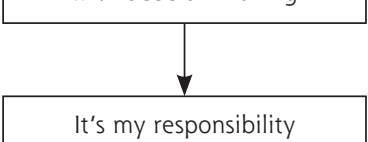

I want to make the decisions for them so it won't

be difficult for them

B

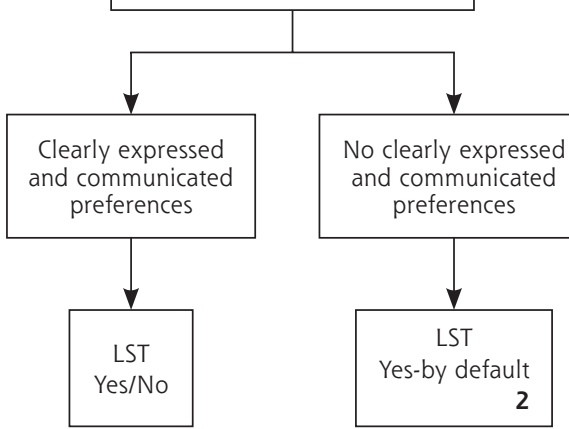

LST $=$ life-sustaining treatment. 


\section{Table 1. Five Scenarios of Patients' Preferred Style of Delegating Decision-Making Authority

Scenario and Patient Descriptive Comment \\ Scenario A: A 61-year-old patient with stage 4 lung cancer, separated from his wife for more than 10 years \\ Scenario B: A 73-year-old patient with advanced chronic obstructive pul- monary disease \\ Scenario C: An 80-year-old patient with colon cancer \\ Scenario D: An 85-year-old patient with end-stage heart failure \\ Scenario E: A 58-year-old patient with stage 4 lung cancer who is undergo- ing palliative radiation \\ "This is my own business and not for anyone else to meddle with. You get me the paperwork and \\ I will write it down today-I don't want anyone to put me on a breathing machine ever again." \\ "It's all right here, I wrote it all down and crossed all t's. I don't want to make it so hard on my kids like it was for me with my mom. They all have a copy of it and know exactly what I want." \\ "My daughters all know what to do, and I know they will make good choices. I don't need to waste ink on this, but we have talked a lot about my cancer, and I told them 'Don't let me linger.'" \\ "We have been married for over 60 years, I trust my wife completely to do the right thing when things get bad. I don't have to tell her what to do." \\ At the beginning of a discussion to address code status he states: "I don't want to talk about resuscita- tion. I don't even want to think about those things. You better stop talking about this stuff." When gently prodded about his experience with hospitals and ICUs, he mentions a friend who died "as a vegetable-you know, he was with a machine for breathing and couldn't do anything for himself, and he was like that for over 6 months. He was in horrible shape."}

ICU = intensive care unit.

Note: The scenarios are labeled A through $E$ to correspond to the focus-group-derived quotes $A$ through $E$ in Figure 1

The remaining 2 life-sustaining treatment by default outcomes, 1 and 2, originate in the decision-making style of deciding for oneself. Patients may explicitly adopt the I decide style and make a clear decision but not communicate it effectively to physicians or surrogates. These pathways expose an often insufficiently appreciated aspect of patient autonomy: regardless of whether a patient wants to take responsibility for his or her own decisions or does not want to burden others with end-of-life decisions, there is no guarantee against the provision of life-sustaining treatment by default, even if a patient does not want it.

Our conceptualization allows us to identify the common feature of the 5 distinct pathways to lifesustaining treatment by default: the failure of some patients to exercise their autonomy by explicitly and clearly communicating decisions or value-based preferences, either to their physicians or to their surrogate decision makers. This failure is compounded when patients lack legal surrogates and advance directives (about $5 \%$ of patients dying in intensive care units). ${ }^{25}$ Physicians should take what White et al describe as a facilitative role ${ }^{26}$ by advising all patients about the risks of life-sustaining treatment by default and encouraging them to express clear and preferred directives to their physicians, legal surrogates, or close friends who might act as their surrogates.

\section{PREVENTING LIFE-SUSTAINING TREATMENT BY DEFAULT}

Our reconceptualization of surrogate decision making proposes that, when surrogates request everything be done to sustain a patient's life, they should be assumed to be burdened by a lack of input from the patient and experiencing high levels of stress. ${ }^{3}$ The surrogates' decision-making process may be further complicated by the multiple sources surrogates draw on to make their own prognostic judgments. ${ }^{27}$

When patients communicate their preferences to surrogates, their role is to report the patients' preferences to clinicians. ${ }^{7,27}$ Surrogates do not experience making such a report as making a decision, because there are no options to consider. For surrogates, reporting patients' preferences is much less burdensome than the decision making required when patients' preferences are unknown. The nuances and complexities of smaller day-to-day decisions are often laced with more uncertainty than big-picture decisions, such as DNAR (do not attempt resuscitation) status or placement of a PEG (percutaneous endoscopic gastrostomy) tube. Sometimes stated preferences do not readily translate to specific clinical decisions, such as whether antibiotics should be given for treatable pneumonia. Even so, such decisions will still be easier for surrogates who can confidently report treatment goals previously expressed by patients than for surrogates who had no guidance. The ability of surrogates to make a report, rather than a decision, should reduce the occurrence of life-sustaining treatment by default, and physicians should attempt to increase the frequency with which surrogates can make reports.

Preventing life-sustaining treatment by default outcomes 1,2 , and 3 build on pathways $\mathrm{A}, \mathrm{B}$, and $\mathrm{C}$, in which patients have clearly made a decision. For these patients, physicians should strongly and, if necessary, repeatedly encourage patients to follow through by communicating their intentions clearly, orally or in writing, to their surrogates or to their physicians.

It will be more challenging to prevent life-sustaining treatment by default outcomes 4 and 5 , because patients in pathways $\mathrm{D}$ and $\mathrm{E}$ do not have clear deci- 
sions to communicate. Physicians should encourage these patients to exercise their autonomy and express their decisions or general values to their surrogates.

The patient in Table 1, scenario D, should be informed that although he has made a good start, counting on his wife to know what he wants risks life-sustaining treatment by default, and he should be encouraged to express his values and preferences to her so she can report them when he cannot. He also should be reminded that even though he trusts his wife to make the right choices, she might be burdened with making a decision without further guidance. End-of-life planning is often best accomplished with both the patient and the potential surrogate present. Such planning is not a single event but an ongoing process, and what is decided in one setting, eg, in the outpatient clinic, may need to be reevaluated and readdressed in another, eg, during an acute hospitalization. The patient in Table 1, scenario E, requires stronger recommendations to communicate preferences to surrogates or physicians. Physicians should not hesitate to emphasize to a patient the risks of not dealing with the possibility of serious illness and thereby life-sustaining treatment by default.

Undertaking the above strategies may reduce the frequency with which patients elect life-sustaining treatment. We emphasize, however, that the primary goal of preventing life-sustaining treatment by default is not to alter the frequency with which life-sustaining treatment is authorized. Our goals are (1) to decrease the frequency of life-sustaining treatment by default, (2) to increase the frequency of clearly made and communicated decisions, and, therefore, (3) to enable more surrogates to make reports rather than burdensome decisions

Our proposed strategies for preventing life-sustaining treatment by default have an important implication for the decades-old debate about which is more important, completing advance directives or securing medical power of attorney. ${ }^{28-33}$ Both are at risk of being unhelpful: the former may not express a clear decision, and the latter may only name a surrogate. Our emphasis is different and independent of the specific means by which patients elect to communicate their decisions; we emphasize encouraging and supporting patients to make clearly expressed decisions and values and then to communicate these decisions and values to their surrogates or physicians. Advance directives should be regarded as one, but not the only, tool patients can use to communicate their decisions effectively to others.

We have proposed important strategies for preventing life-sustaining treatment by default. Our strategies will help family members who act as surrogate decision makers to report the patient's end-of-life preferences and thus reduce the biopsychosocial burdens of having to make decisions under conditions of uncertainty. Health care organizations can strengthen their organization's professionalism by increasing the frequency with which end-of-life decisions implement respect for patients' autonomy.

To read or post commentaries in response to this article, see it online at http://www.annfammed.org/cgi/content/full/9/3/250.

Key words: Life-sustaining treatment by default; personal autonomy; end-of-life care; life support care; decision making; terminal care

Submitted June 24, 2010; submitted, revised, October 26, 2010; accepted, November 23, 2010.

Funding support: Drs Braun and McCullough were supported by the Department of Veterans Affairs, VA-HSRED-IIR-02-224: A Culturally Sensitive Values-Guided Aid for End-of-life Decision Making. Dr Braun was also supported in part by funds from the Department of Health and Human Services (DSSH), Health Resources and Services Administration (HRSA) Bureau of Health Professions (BHPR), under Geriatric Academic Career Award $1 \mathrm{KO} 1 \mathrm{HP00074}$. Dr. Braun is staff physician at the Michael E. DeBakey Veterans Affairs Medical Center, Houston, Texas, and physician scientist at the Houston Department of Veterans Affairs, Veterans Health Administration, Health Services Research and Development Center of Excellence.

Disclaimer: The information or content and conclusions are those of the authors and should not be construed as the official position or policy of, nor should any endorsements be inferred by the DHHS, HRSA, BHPR, the VA, or the US Government.

\section{References}

1. Field MJ, Cassel CK. Approaching Death: Improving Care at the End-ofLife. Washington, DC: National Academy Press;1997.

2. Lynn J, Goldstein NE. Advance care planning for fatal chronic illness: avoiding commonplace errors and unwarranted suffering. Ann Intern Med. 2003;138(10):812-818.

3. Braun UK, Beyth RJ, Ford ME, McCullough LB. Voices of African American, Caucasian, and Hispanic surrogates on the burdens of end-of-life decision making. J Gen Intern Med. 2008;23(3):267-274

4. Braun UK, Beyth RJ, Ford ME, McCullough LB. Defining limits in care of terminally ill patients. BMJ. 2005;53(5):S137-S138.

5. Braun UK, Ford ME, Beyth RJ, McCullough LB. The physician's professional role in end-of-life decision making: Voices of racially and ethnically diverse physicians. Patient Educ Counsel. 2009;Nov 28 [Epub ahead of print].

6. Azoulay E, Pochard F, Kentish-Barnes N, Chevret S, Aboab J, Adrie C, Annane D, et al; FAMIREA Study Group. Risk of post-traumatic stress symptoms in family members of intensive care unit patients. Am J Respir Crit Care Med. 2005;171(9):987-994.

7. Braun UK, Naik AD, McCullough LB. Reconceptualizing surrogate decision making: reporting versus deciding for others. Ann Fam Med. 2009;7(3):249-253.

8. Chervenak FA, McCullough LB. Clinical guides to preventing ethical conflicts between pregnant women and their physicians. Am J Obstet Gynecol. 1990;162:303-307.

9. Forrow L, Arnold RM, Parker LS. Preventive ethics: expanding the horizons of clinical ethics. J Clin Ethics. 1993;4:287-294.

10. Lo B. Improving care near the end of life. Why is it so hard? JAMA. 1995;274(20):1634-1636. 
11. Miles SH, Koepp R, Weber EP. Advance end-of-life treatment planning. Arch Intern Med. 1996;156(10):1062-1068.

12. McCormick RA. To save or let die: the dilemma of modern medicine. JAMA. 1974;229(2):172-176.

13. Tomlinson T, Brody H. Ethics and communication in do-not-resuscitate orders. N Engl J Med. 1988;318(1):43-46.

14. Crippen D. Medical treatment for the terminally ill: the 'risk of unacceptable badness'. Critical Care. 2005;9(4):317-318.

15. Beauchamp TL, Childress JF. Principles of Biomedical Ethics, 6th ed. New York: Oxford University Press, 2009.

16. Brody BA. Life and Death Decision Making. New York: Oxford University Press, 1988.

17. Braun UK, McCullough LB, Ford ME, Espadas D, Beyth RJ. End-oflife care across race and ethnicities: voices of patients, surrogates, and physicians.J Am Geriatr Soc. 2005;53(5): S137-S138.

18. Shalowitz Al, Garrett-Mayer E, Wendler D. The accuracy of surrogate decision makers. Arch Intern Med. 2006;166:493-497.

19. Hare J, Pratt C, Nelson C. Agreement between patients and their self-selected surrogates on difficult medical decisions. Arch Intern Med. 1992;152(5):1049-1054.

20. Sulmasy DP, Terry PB, Weisman CS, et al. The accuracy of substituted judgments in patients with terminal diagnoses. Ann Intern Med. 1998;128:621-629.

21. Sulmasy DP, Haller K, Terry PB. More talk, less paper: predicting the accuracy of substituted judgments. Am J Med. 1994 May;96(5):432-438.

22. Suhl J, Simons P, Reedy T, Garrick T. Myth of substituted judgment. Surrogate decision making regarding life support is unreliable. Arch Intern Med. 1994 Jan 10;154(1):90-96.

23. Vig EK, Taylor JS, Starks H, Hopley EK, Fryer-Edwards K. Beyond substituted judgment: How surrogates navigate end-of-life decisionmaking. J Am Geriatr Soc, 2006;54(11):1688-1693.
24. Marks MA, Arkes HR. Patient and surrogate disagreement in endof-life decisions: can surrogates accurately predict patients' preferences? Med Decis Making. 2008;28(4):524-531.

25. White DB, Curtis JR, Wolf LE, et al. Life support for patients without a surrogate decision maker: Who decides? Ann Intern Med. 2007;147:34-40

26. White DB, Malvar G, Karr J, Lo B, Curtis R. Expanding the paradigm of the physician's role in surrogate decision-making: An empirically derived framework. Crit Care Med. 2010;38(3):743-750.

27. Boyd EA, Lo B, Evans LR, Malvar G, Apatira L, Luce JM, White DB. "It's not just what the doctor tells me:" Factors that influence surrogate decision-makers' perceptions of prognosis. Critical Care Medicine. 2010; 38(5): 1270-1275

28. Tolle SW, Tilden VP, Nelson CA, Dunn PM. A prospective study of the efficacy of the physician order form for life-sustaining treatment. J Am Geriatr Soc. 1998 Sep;46(9):1097-1102.

29. Fagerlin A, Schneider CE. Enough. The failure of the living will. Hastings Cent Rep. 2004;34(2):30-42.

30. Emanuel EJ. Living wills: are durable power of attorneys better? Hastings Cent Rep. 2004;34(6):5-6; author reply 6-7.

31. Schneiderman LJ, Pearlman RA, Kaplan RM, Anderson JP, Rosenberg EM. Relationship of general advance directive instructions to specific life-sustaining treatment preferences in patients with serious illness. Arch Intern Med. 1992;152(10):2114-2122.

32. Emanuel LL, Emanuel EJ. The medical directive: a new comprehensive advance care instrument. JAMA. 1989;261:3288-3293.

33. Teno JM, Licks S, Lynn J, et al. for the SUPPORT investigators. Do advance directives provide instructions that direct care? J Am Geriatr Soc, $1997 ; 45: 508-512$ 